\title{
A Dynamic on-Grid Solar Power System Using a Bi- Directional Counter Meter
}

\author{
Mukthar Bidemi Opeloyeru, Prof. Dr. R. Nejat Tuncay \\ Faculty of Engineering, Power Electronics and Clean Energy System Department, Istanbul Okan University, Turkey
}

\begin{abstract}
Recent advancement in technology has led to a remarkable increase in solar cell efficiency while causing a reduction in the expenses of $\mathrm{PV}$ systems and the adoption of $\mathrm{PV}$ systems as a reliable source of energy globally. To further reduce the entry barrier of PV systems, most governments have introduced several incentives including a Net-metering tariff which uses a bi-directional meter for grid-connected PV systems. This research work focuses on the design and simulation of a $2 \mathrm{~kW}$ grid-connected system with an integrated bi-directional metering unit. The design, modelling, simulation, and analysis of the developed system were done using the Simulink interface of the MATLAB suite. The system essentially consisted of a "Perturb and Observe" MPPT system, a phase-locked loop (PLL), an LCL filter, and a Mosfet-based single phase inverter system. In comparison to existing studies, the research features an integrated bi-directional metering unit to give a more practical overview of the implementation and operation of the counter-based bidirectional meters and net metering. The simulation result obtained from running the model at different levels of irradiance and the response of integrated bidirectional meter indicated a functional system capable of metering energy in both modes.
\end{abstract}

Keywords - Bi-directional Meter, Grid Connected PV system, LCL filter, PID Controller, MPPT, P\&O Algorithm., MATLAB/SIMULINK.

\section{INTRODUCTION}

$\mathrm{T}$ he growing environmental concern over the usage of fossil-based energy sources and the relative advancement in science and technology has consequently lead to the widespread call for the adoption of renewable energy sources for energy generation.

Renewable energy has been adjudged to be a promising alternative to fossil as they are relatively cleaner and more permanent. The common renewable energy sources are wind, photovoltaic, wave, biomass, and tidal as substitute sources to yield electricity (Atiq \& Soori, 2017). The global energy report for 2012 indicated that over $16 \%$ of the world's energy consumption comes from renewable energy sources. While this might be considered a relatively small proportion, Johnson (2013), noted that over half of the new electric power installations in the year 2011 were from a renewable energy source and this was proposed to likely be the trend for the future.

Although there has been widespread adoption of several renewable energy solutions over the years, solar energy systems have become the utmost significant source of renewable energy. Solar energy is one of the cleanest forms of energy and the process of harnessing the energy from the sun for various purposes is often without the production of any harmful byproduct or waste.

This study will give a broad overview of the several ways of harnessing solar energy and explore the concept of solar cells and Photovoltaic (PV) arrays. The modelling of the target PV system will then be considered and suitable performance evaluation will be carried out by analyzing the result obtained from the simulation of the system with Matlab Simulink.

\section{Solar Energy Systems}

Solar energy is one of the cleanest forms of energy and the process of harnessing the energy from the sun for various purposes is often without the production of any harmful byproduct or waste.

Nuclear reactions within the sun produce energy that travels to the earth's surface as electromagnetic radiation. The generated electromagnetic radiation is composed of over $50 \%$ infrared, with visible and ultraviolent as a myriad of radiation with diverse electromagnetic spectrum accounting for the remainder. As this radiation travels to the earth, a quota of it is dispersed by molecules and dust in the air consequently sending radiation in all directions and a huge proportion of it back into space. The interaction between the generated electromagnetic radiation and the aforementioned elements leads to the reduction of the solar energy instability by about $40 \%$ while also altering its structure so that the sunlight which touches the globe's surface consists of $50 \%$ evident radiation and $47 \%$ infrared.

Although advancement in science and technology over the years has led to the development of diverse equipment and technological solutions for harnessing solar energy, several factors, however, affect the amount of solar radiation received by any surface.

Khatib \& Elmenreich (2016), listed the geographical location, the local landscape and weather conditions as well as the time of the day as important factors that affect the level of solar radiation a place is exposed to at any given time regardless of the method employed in harnessing the solar energy.

The most common ways by which solar energy is harnessed include the following; 


\section{A. Solar Heating and Cooling systems (SHC)}

These technologies have been designed to harness the heat from the sun for diverse purposes including space heating, pool heating, and cooling for both residential, industrial applications.

Solar cooling systems are essential of two major types: the absorption chiller system and the desiccant variant. The desiccant system essentially leverages the thermodynamics properties of desiccant materials such as silica gel to absorb moisture from the air to improve thermal comfort. Then spent desiccant is further drive via solar heat and the cycle is repeated afresh.

Absorption chiller systems function similarly to the conventional refrigerating system. Common absorption cooling setups employ solar water heating collectors. The absorption cycle is fundamentally driven by a heated fluid from a suitable solar collector.

\section{B. Concentrating Solar Power (CSP)}

These systems are designed to focus the energy of the sun on a specialized surface to drive utility-scale, electric turbines that generate electricity. CSP exists in different format arrangements ranging from the parabolic trough, Fresnel reflectors to dish engines. Common CSP uses well-crafted mirrors to concentrate the thermal energy for driving suitable steam turbines and electricity engines. Concentrating solar power systems also enable energy to be stored for electricity generation at peak periods of the day as well as relatively low night time.

\section{Photovoltaic Systems (PV)}

PV systems essentially consist of solar cells arranged into solar arrays, inverters, converters, energy-storing devices plus other mechanical and electrical equipment to produce DC and AC power. Although fossil fuel is still high in use for most energy demand, there has been a relatively steady increase in the usage and adoption of PV systems in energy generation The development of more efficient solar cells, and the comparative decrease in the cost of acquiring and setting up PV systems have greatly increased the rate of adoption of PV systems as a worthy replacement for fossil fuel-based power generation systems (Mohanty et al., 2016).

\section{i. Overview of the Solar Cell}

This is the fundamental element of photovoltaic systems. When combined in series, solar cells form a photovoltaic panel and when they are further arranged in parallel, they are referred to as a photovoltaic array.

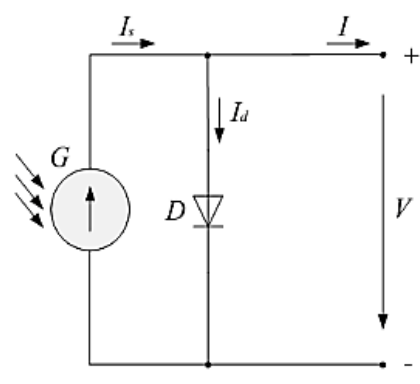

Figure 1. The ideal Solar cell

An ideal PV solar cell is shown in Fig 1.0; G represents the solar radiance, $I_{s}$ is the photo-current generated, $I_{d}$ is the diode current, $\mathrm{I}$ is the output current and $\mathrm{v}$ is the terminal voltage.

The solar cell in its basic form is a simple diode exposed to light. Solar cells are thus prepared from numerous semi-conductors via diverse manufacturing processes. Consequently, the electrical output of solar cells is a function of their intrinsic properties and inward solar energy.

Solar energy is made up of photons at different levels of energy, they get immersed at the p-n junction. The bandgap of semiconductors is of great importance in its energy generation. The bandgap refers to the lowest amount needed to release a bound electron to its free. In operation, photons consisting of energies lesser than the band-gap of the solar cell are relatively unable to produce an electric current. Although Photons with higher energy generate electricity only those matching to the energy band gap while the remains will degenerate as heat (Rodrigues et al., 2011).

\section{ii. Uses of PV systems}

Although diverse uses of PV systems have been developed over the years, the following are some of the common applications of PV systems: water pumping, lighting and traffic signals, microgrids, solar radiation, maximum power point tracking (MPPT), bi-direction metering.

\section{iii. Types of PV systems}

Three major classes of solar PV systems exist Grid-connected (Grid- Tied), Grid/hybrid and Off-grid.

\section{a. Off-grid Solar systems}

Off-grid systems are essentially designed to stand alone as such they are not connected to the main electricity grid; hence a storage battery is often required for use. Zipp, (2015) noted that these PV systems are well suited for users with geographical limitations or needing a more consistent energy source.

\section{b. Grid-Hybrid Solar Power systems}

These systems are tied to the power grid and also features integrated backup circuitry and backup battery. Hence, they are well suited for sensitive installations and facilities where unscheduled power outbreaks could lead to catastrophic failure 
in operations. Battery based grid-tied systems are designed to provide power during emergencies. These hybrid systems essentially require more components and a backup-sub panel is often needed to isolated and power target devices and equipment (Zipp, 2015).

\section{c. Grid-connected Solar Power system}

A grid-connected system uses a standard grid-tied inverter. As such, there is no need for a storage battery. Zipp, (2015) noted that the Grid-connected system is perfect for customers who are already on connected to the electricity grid and want to add solar to their house.

\section{iv. Specfications on On-Grid PV systems}

Unlike Direct current systems, several requirements and specifications must be duly followed to safely combine several alternative current sources. To facilitate safe and efficient adoptions of Grid-connected PV systems, Distribution Network Operators and PV industry experts need to design and constantly review safety and quality specifications. In recent times, several standards have emerged for the interconnectivity of PV systems and utility the International Electro-technical Commission (IEC), Institute of Electrical and Electronics Engineers (IEEE) are well adopted in many countries (Rani \& Sharma, 2017).

The IEE-1547-2018 provides technical specifications for Distributed energy resources and utility electric power systems to test their interconnection and inter-operability.

The IEE-1547-2018 essentially dictates the general requirements and also specifies the response to abnormal conditions, islanding and as well as installation evaluation, commissioning and a couple of other relevant specifications.

\section{v. Research Gap in On-grid PV systems}

Several researchers have designed different variants of grid-connected PV systems in recent times. Atiq \& Soori, (2017) designed and simulated a Grid-tied PV system comprising of an MPPT controller, a boost converter, and LC filter amongst other functional parts. The design was simulated with the Simulink Environment of the Matlab IDE and was tested with a $2.75 \mathrm{~kW}$ three-phase load.

Dolas et al., (2020) designed and analyzed a Grid-tied PV system to study the behaviour and performance of this aforementioned PV system. The Researcher duly noted the presence of harmonics in the three-phase voltage and current waveform relative to the supplied form the mains which were 120 degrees apart and having the same magnitude.

Although several functional Grid-Tied PV systems are existing in recent times, the proposed design in this research work will include in its architecture a functional bi-directional meter. The design will be developed and simulated with the Simulink interface of Matlab Suite.

\section{METHODOLOGY}

\section{A. System Description}

The designed model essentially consists of a PV array and a single-phase inverter. Maximum Power Point Tracking (MPPT) is implemented in the boost converter using a Simulink model implementing the 'Perturb \& Observe' technique. The block overview of the model is given in Figure 1 below.

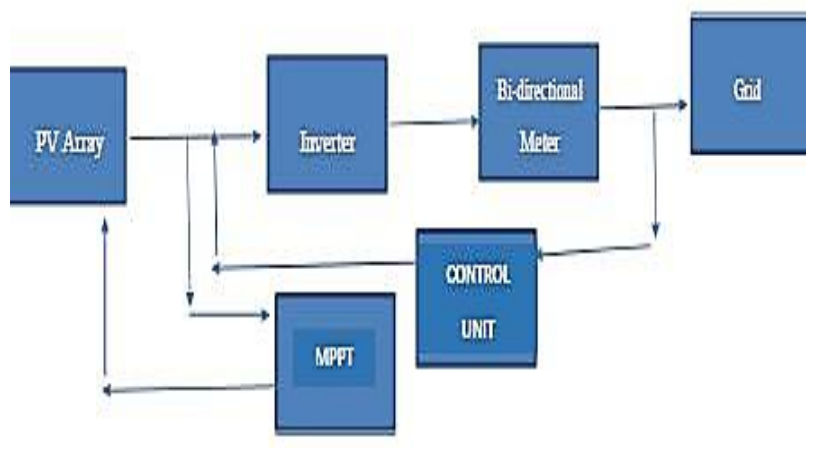

Figure 1. Block diagram of the designed system

\section{B. Open Circuit Voltage (VOC)}

Open circuit voltage refers to peak voltage available when no current is been drawn from the cells.

\section{Switching Frequency}

In a pulse width modulation process, the switching frequency refers to the frequency at which the DC voltage is switch between both logic levels.

Frequency in switching a converter or an inverter is the rate at which the switching device is turned on and off. Usual frequencies vary from some kilohertz $(\mathrm{kHz})$ to some megahertz $(\mathrm{MHz})(20 \mathrm{kHz}-2 \mathrm{MHz})$.

Generally, an increased switching frequency allows for a reduction in other components such as inductors, resistors etc and consequently allows for a more compact housing.

Basic parameters for the models are shown below.

\begin{tabular}{|c|c|c|}
\hline 1 & Open Circuit Voltage & $493.5 \mathrm{~V}$ \\
\hline 2 & Switching Frequency of Inverter & $10 \mathrm{kHz}$ \\
\hline 3 & Grid Voltage & $230 \mathrm{~V}$ \\
\hline 4 & Grid frequency & $50 \mathrm{~Hz}$ \\
\hline
\end{tabular}

\section{Modelling of the PV System}

The designed system essentially consists of the following parts

1. The PV array

2. Maximum power point tracking

3. The phase lock loop PLL

4. A single-phase inverter 


\section{E. Modelling of PV Array}

Solar PV system captures sunlight and converts it to electricity. The output of the solar cell is dependent on two major factors, ambient temperature, and irradiation. The change in the output power of a Photovoltaic system due to a change in the cloud is often a major technical drawback. Fluctuation in voltage and the light flickering is amongst the most common challenges faced due to cloud transients. The irradiation and the temperature in this research are duly modeled via the constant block of the Simulink interface.

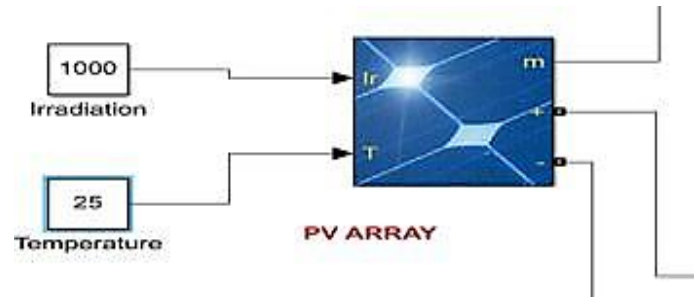

Figure 2. Irradiation and Temperature block

A change in any of the aforementioned factors either positively increases or decreases the output of the solar cell. The PV array consists of 1parallel string. Each string has 11 Zytech ZT190S Engineering Technology modules connected in series.

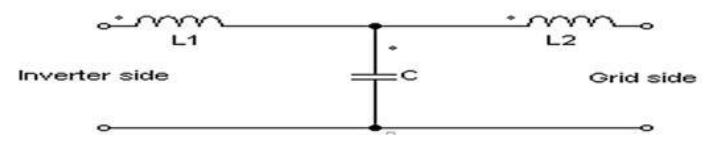

Figure 4. LCL filter
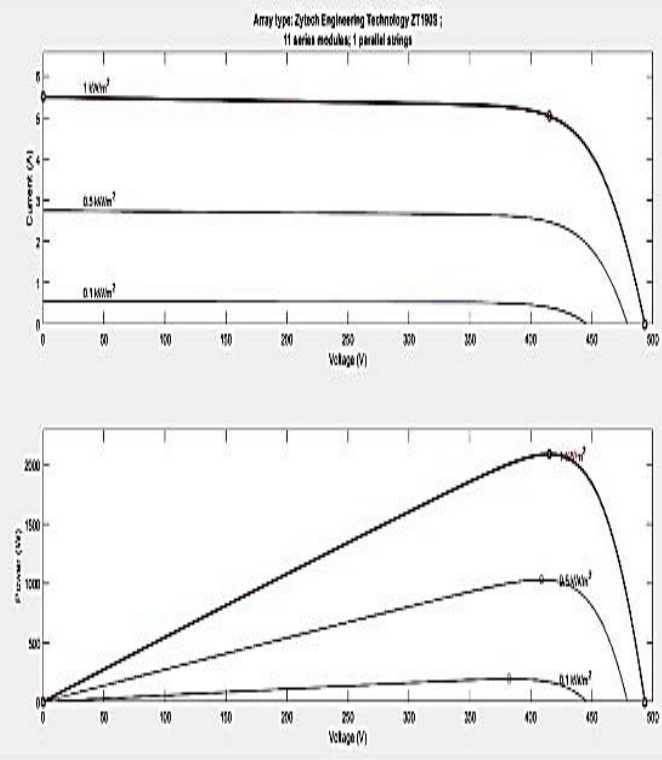

Figure 3. Irradiation and temperature simulation

\section{F. LCL filter}

The presence of harmonics in power systems can cause several devastating effects on connected loads especially sensitive equipment as such an LCL filter is often a desired addition to grid-connected PV systems. Since the value of inductance needed is proportional to the capacity of the system, there is often an increase in the difficulty of achieving practical filters for very large systems due to poor dynamic responses and associated costs. The LCL filer helps to reduce the switching frequency harmonics between the grid and the inverter in a grid-connected setup. (Kahlane et al., 2014).

\section{G. Capacitor Design}

The capacitor used is essentially designed based on the reactive power immersed at the rated conditions. The reactive power represented as "Q" is often limited to 5\% of the rated power

$$
Q=\frac{V^{2}}{(0.5 * 2 \pi f C)}
$$

$Q=\frac{V^{2}}{(0.5 * 2 \pi f C)}=5 \%$ of $S$

$C=\frac{0.05 \times 2000}{\left(230^{2} \times 2 \times \pi \times 50\right)}=6.01 u F$

\section{Inductor Design}

Inverter side inductor $\mathrm{L} 1$ is selected based on the maximum permissible current ripple. The current ripple is limited to $20 \%$ of the rated current

$$
L_{1}=\frac{V_{D C}}{4 \times F_{s w} \times \Delta I_{p p \max }}
$$

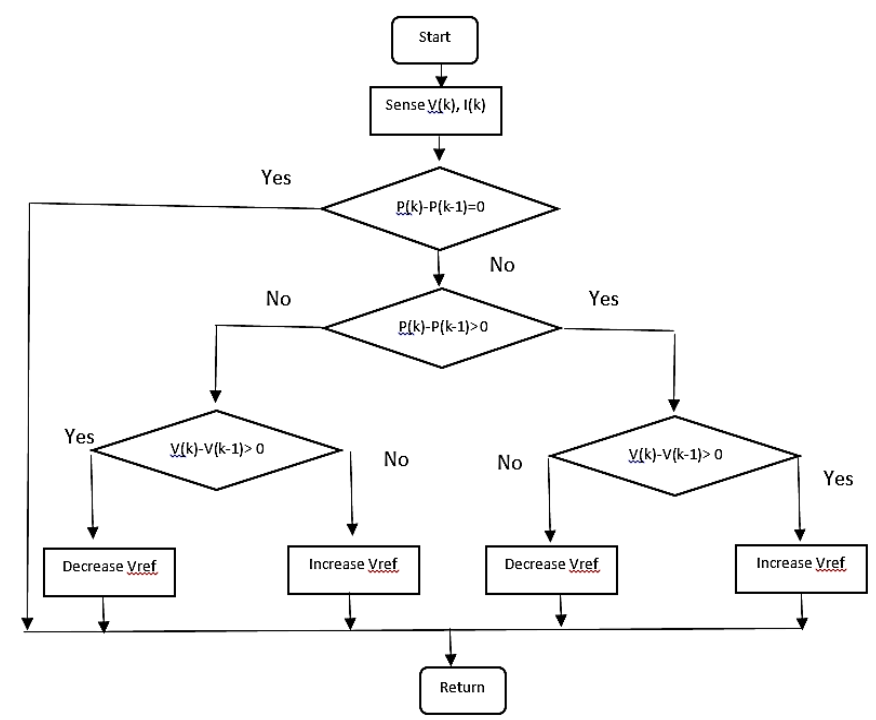

Figure 5. The Perturb and Observe Algorithm 


$$
L_{1}=\frac{V_{D C}}{4 \times 10000 \times 8.69 \times 1.414 \times 0.2}=4.06 \mathrm{mH}
$$

The total inductance in the LCL is selected based on the maximum voltage drop across the inductor which is limited to $10 \%$ of the rated voltage. Thus

$$
\begin{aligned}
& V_{L_{1}+L_{2}}=I \times X_{L_{1}+L_{2}}=I \times 2 \pi f\left(L_{1}+L_{2}\right) \\
& I \times 2 \pi f\left(L_{1}+L_{2}\right)=10 \% \text { of } V \\
& L_{1}+L_{2}=\frac{10 \% \text { of } V}{S / V) \times 2 \pi f} \\
& L_{1}+L_{2}=\frac{0.1 \times 230^{2}}{2000 \times 2 \times \pi \times 50}=8.41 \mathrm{mH} \\
& L_{2}=8.41 \mathrm{mH}-4.06 \mathrm{mH}=4.35 \mathrm{mH} \\
& \text { H. Modeling the Maximum Power Point Tracking }
\end{aligned}
$$

\section{H. Modeling the Maximum Power Point Tracking}

The I-V characteristics of the photovoltaic module are dependent on the load as such the power obtained from the module differs at a different operating point. The maximum power point tracking ensures that the maximum power is obtained from the load at every condition. MPPT works by controlling the duty cycle or the operating voltage of a photovoltaic system to ensure maximum power at all times. Although a myriad of MPPT algorithms have been developed over the years, the most common algorithms are given below:

\section{Perturb and Observe $(P \& O)$}

The most commonly used algorithm is the " perturb and observe algorithm". The algorithm essentially involves a perturbation of the duty cycle or operating voltage in comparison with the generated power. This algorithm ensures that the Maximum Power-Point is obtained.

\section{Incremental Conductance}

This algorithm is relative more robust and works by comparing the incremental conductance with the instantaneous conductance and adjusting the duty cycle accordingly.

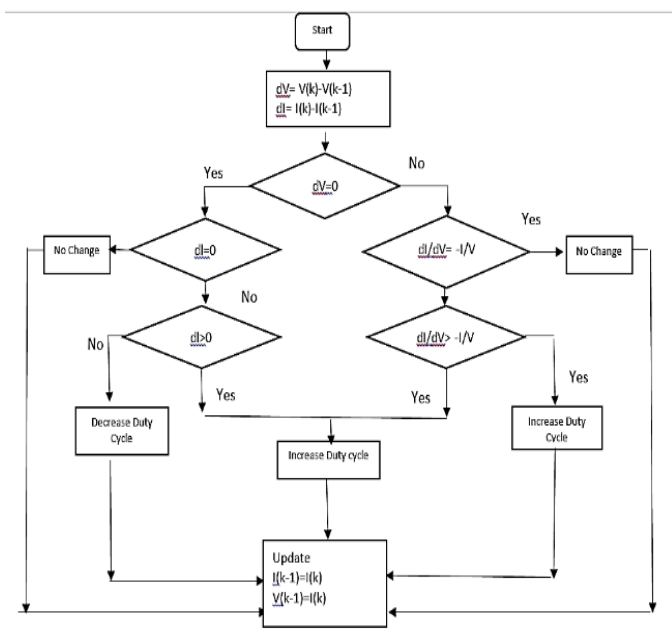

Figure 6. Incremental Conductance Algorithm

The incremental conductance algorithm works on the priciple that the maximum power point is essentially a constant fraction of the open-circuit voltage.

\section{Inverter}

Inverters do convert $\mathrm{DC}$ to $\mathrm{AC}$, which can either be singlephase or multi-phase. Several topologies exist for both the single-phase and multi-phase inverters. An inverter is made up of switches that are turned in such a way that the upper and lower switches are never on at the same time to avoid shortcircuiting the DC source. (Khatib \& Elmenreich, 2016)

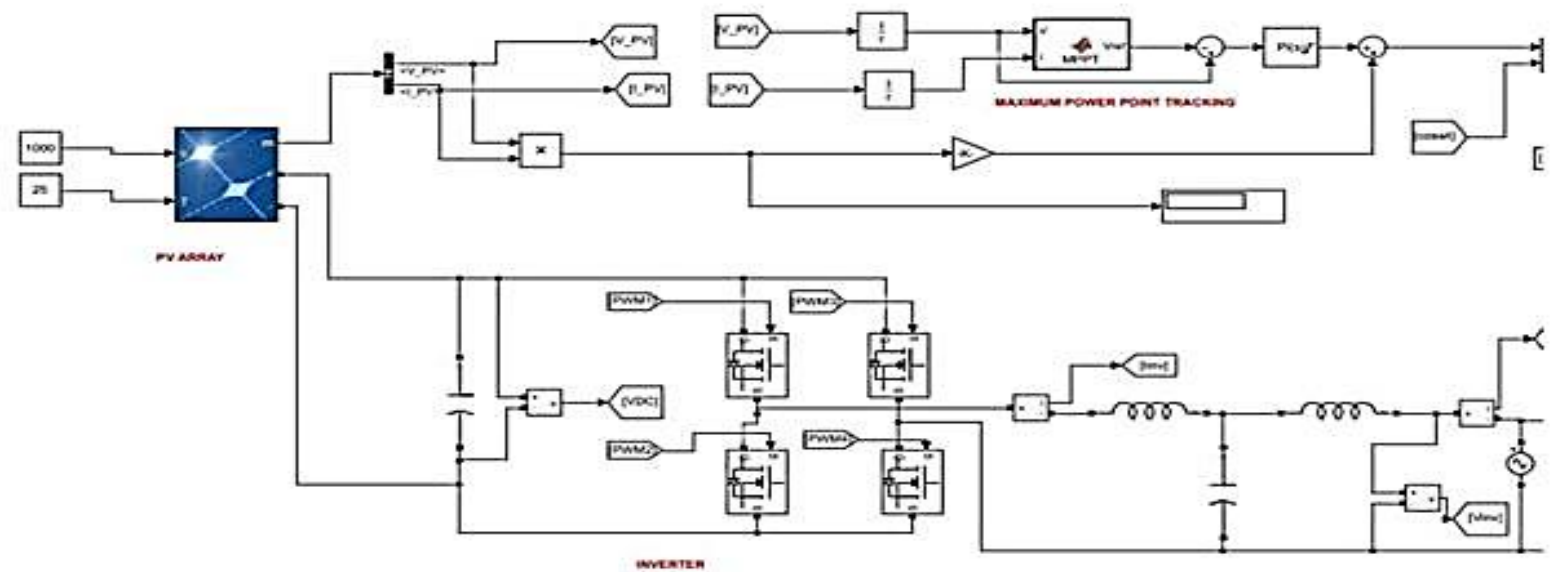

Figure 7. Inverter Schematic 


\section{J. Phase Locked Loop (PLL)}

A mismatch in the frequency of the grid and inverter could result in diverse conditions which could lead to the damage of electronic devices. Since the frequency of the grid often changes with variation in loading, it is of great importance that a suitable phase lock loop is integrated into the system.

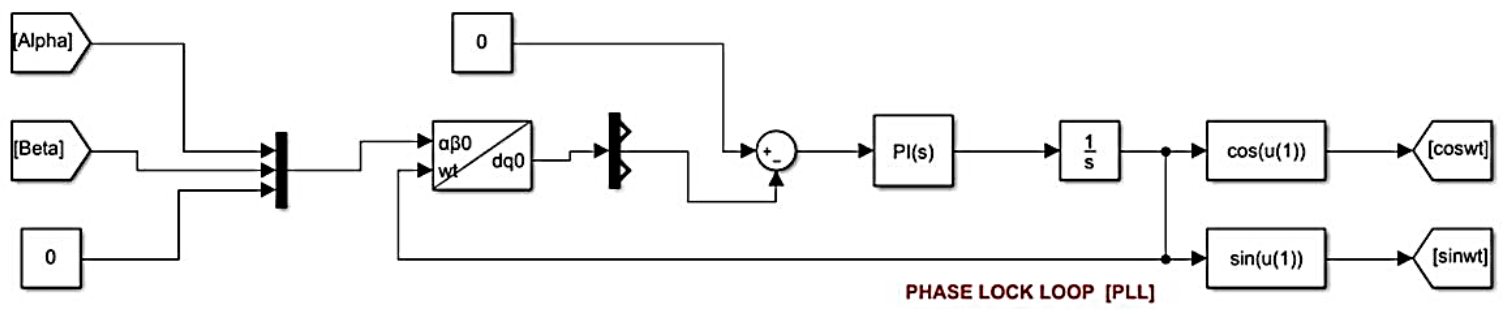

Figure 8. Phase-Locked Loop

The Phase lock Loop essentially adjusts a voltage or currentdriven oscillator to produce an output signal with a synchronized phase as the input signal.

\section{K. Bi-directional Metering}

The bidirectional meter essentially consists of a bi-directional counter which increments its value if the load requirement is more than the inverter output (sourcing from the grid) and decrements when the load requirement is less than the available inverter output. The bi-directional counter thus gives a net reading over some time.

The bi-directional counter model consists of the input block, a bi-directional counter subsystem as seen in figure 9
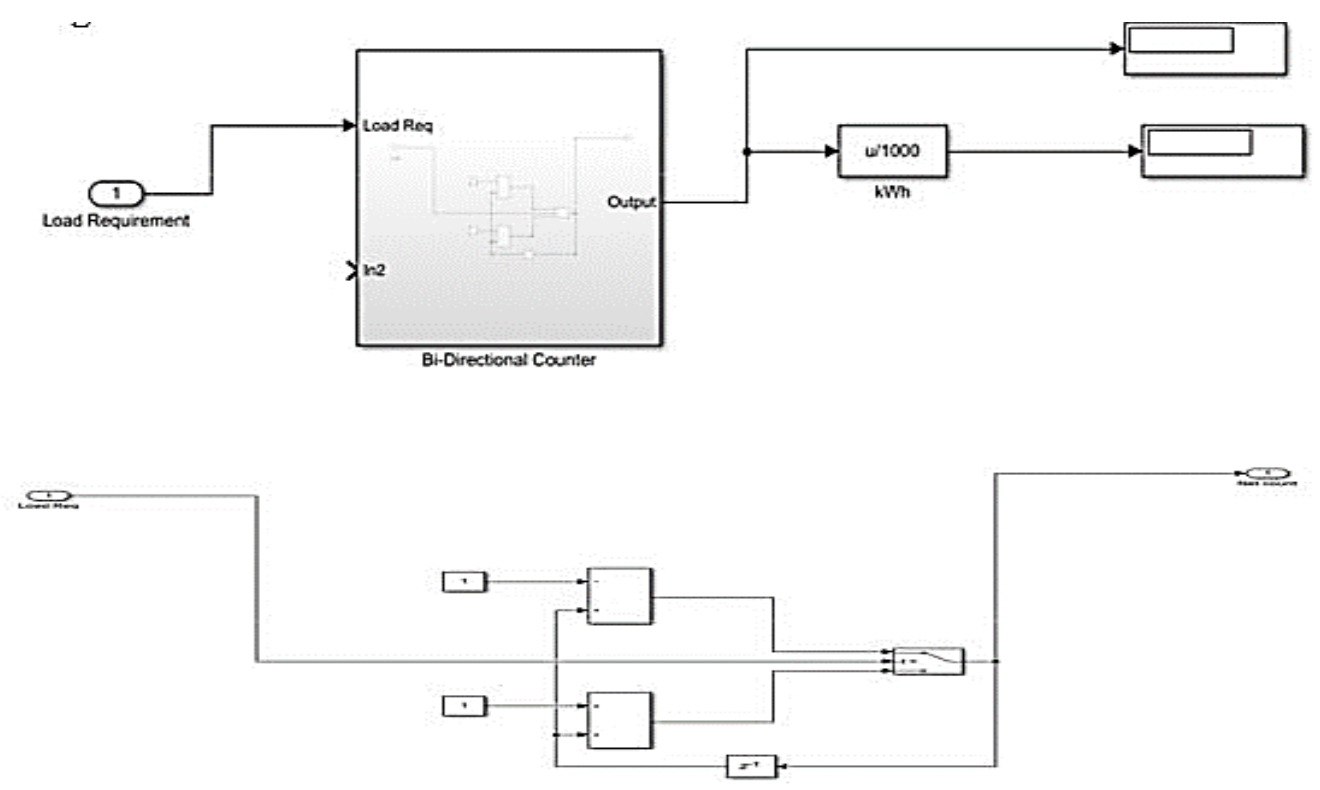

Figure 9. Bi-directional metering Unit

The counter subsystem is made of a series of summation, delay and switch blocks to effectively achieve a negative or positive counter as dictated by the program logic. 


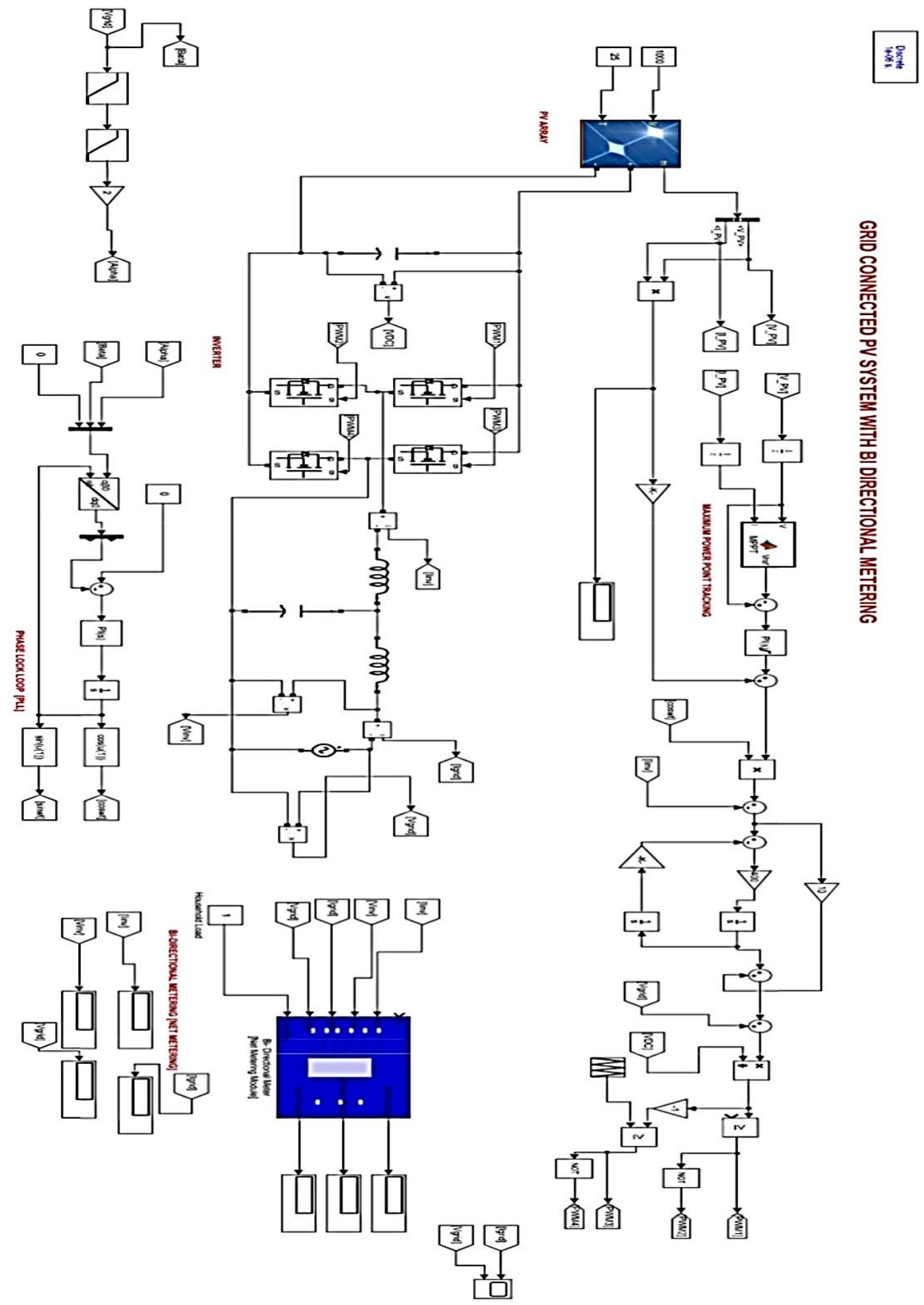

Block Diagram of the designed system

III. RESULT AND PERFORMANCE EVALUATION

\section{A. Model Description}

A single-phase grid-connected photovoltaic system was thus designed and simulated using the Simulink module of the Matlab Suite. The PV system essentially consists of a
PV array, a DC-AC inverter, MPPT unit, the PLL unit and a bi-directional metering unit. The system was tested at $1000 \mathrm{~W} / \mathrm{m}^{2}$ and $800 \mathrm{~W} / \mathrm{m}^{2}$ irradiation levels to evaluate the performance and output of the overall system. 


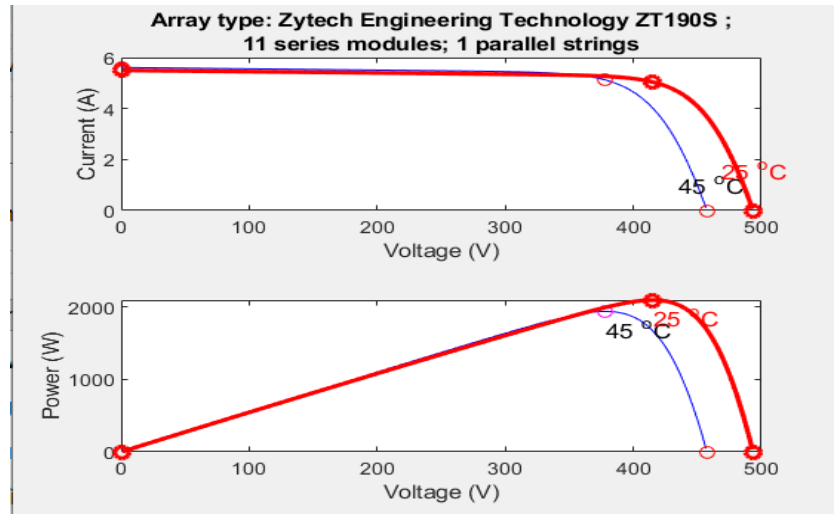

Figure 10. Expected MPPT point at $1000 \mathrm{~W} / \mathrm{m}$ and $25^{\circ} \mathrm{c}$

\section{B. Performance Evaluation of the PV array and MPPT}

A functional maximum power point tracking essentially extracts the maximum obtainable power from PV modules by making them operate at the most efficient voltage (Maximum Power Point Technique). The developed system uses the "Perturb and Observe" algorithm and its performance was evaluated by comparing the expected output at the target irradiance level and temperature with the obtained values during simulation.

i. Evaluation at $1000 \mathrm{~W} / \mathrm{m}^{2}$ irradiance and $25^{\circ} \mathrm{C}$

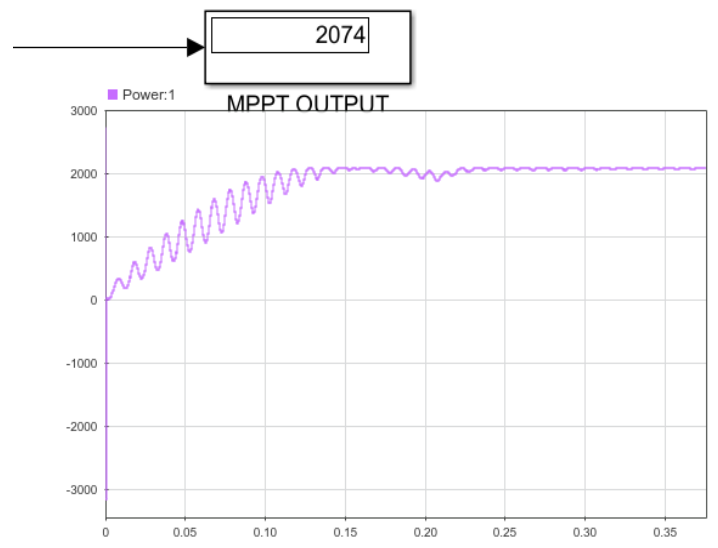

Figure 11. Simulation MPPT point at $1000 \mathrm{~W} / \mathrm{m}$ and $25^{\circ} \mathrm{C}$

The characteristic I-V plot for $1000 \mathrm{~W} / \mathrm{m}^{2}$ and a temperature of $25^{\circ} \mathrm{C}$ for the selected PV configuration is given in Figure 10

The I-V Plot of the selected PV array shows a value of $2091.7512 \mathrm{~W}$ as the peak point obtainable at $1000 \mathrm{~W} / \mathrm{m}^{2}$ irradiation and $25^{\circ} \mathrm{C}$ temperature.

Figure 11 clearly shows a steady rise in the value of the power till the peak point was obtained at an average reading of $2090 \mathrm{~W}$ as compared to the expected value of $2091.7512 \mathrm{~W}$ thus indicating a fully functional MPPT system.

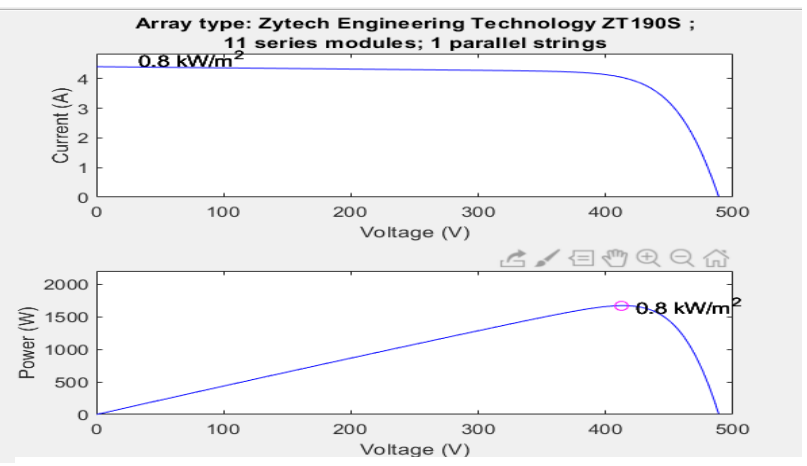

Figure 12. Standard MPPT point at $800 \mathrm{~W} / \mathrm{m}^{2}$ and $25^{\circ} \mathrm{C}$

\section{ii. Evaluation at $800 \mathrm{~W} / \mathrm{m}^{2}$ irradiance and $25^{\circ} \mathrm{C}$}

The performance evaluation of the MPPT unit was repeated at an irradiance value of $800 \mathrm{~W} / \mathrm{m}^{2}$ and a plot of the standard

Performance was compared to the performance generated by the simulation model as seen in Figures 12 and 13 which clearly shows a relatively effective MPPT algorithm.

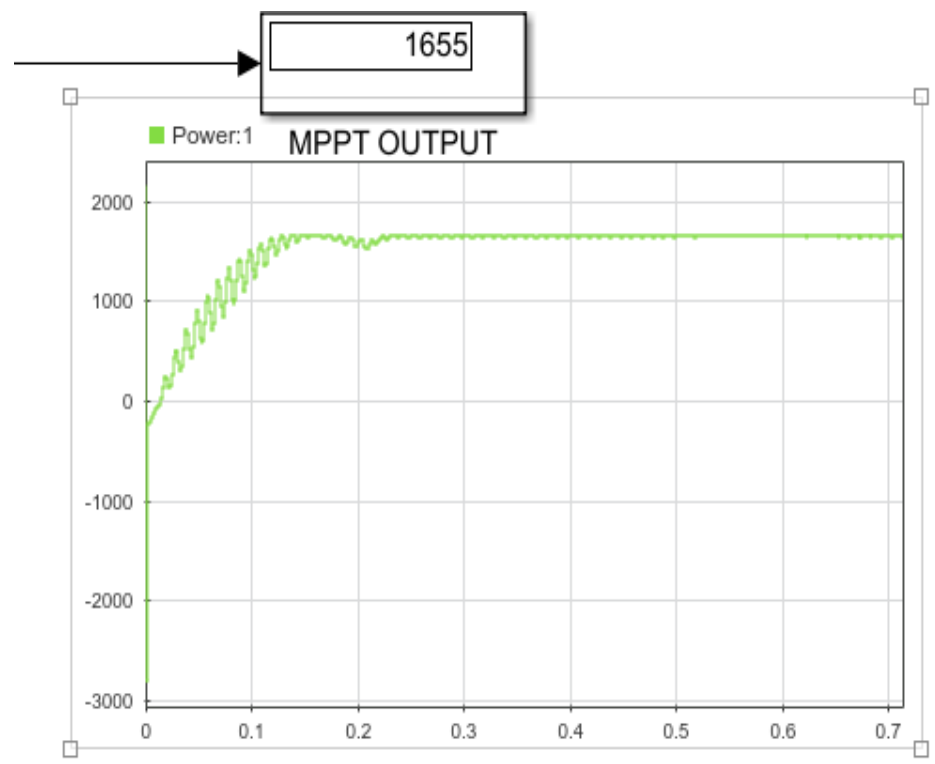

Figure 13. Simulation. MPPT point at $800 \mathrm{~W} / \mathrm{m}^{2}$ and $25^{\circ} \mathrm{C}$

\section{Current and Voltage Output}

The current profile of both the grid and the PV system is seen in the figure below. 


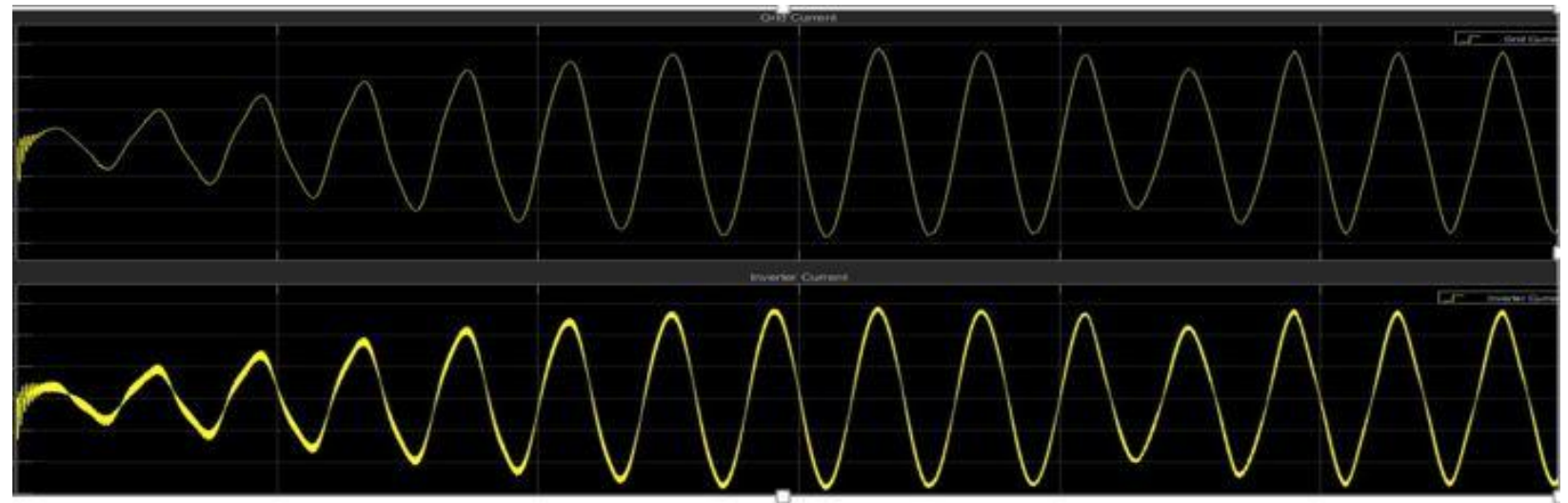

Figure 13. Inverter current and Grid current fault profile

\section{Metering Unit}

The metering unit essentially implements a net-metering arrangement such that a PV system user can either send electricity to the grid or source from the grid as the need arises. This simulation result shows that the meter was able to generate a net reading by counting in both directions depending on the ratio of the load requirement and the grid supply.

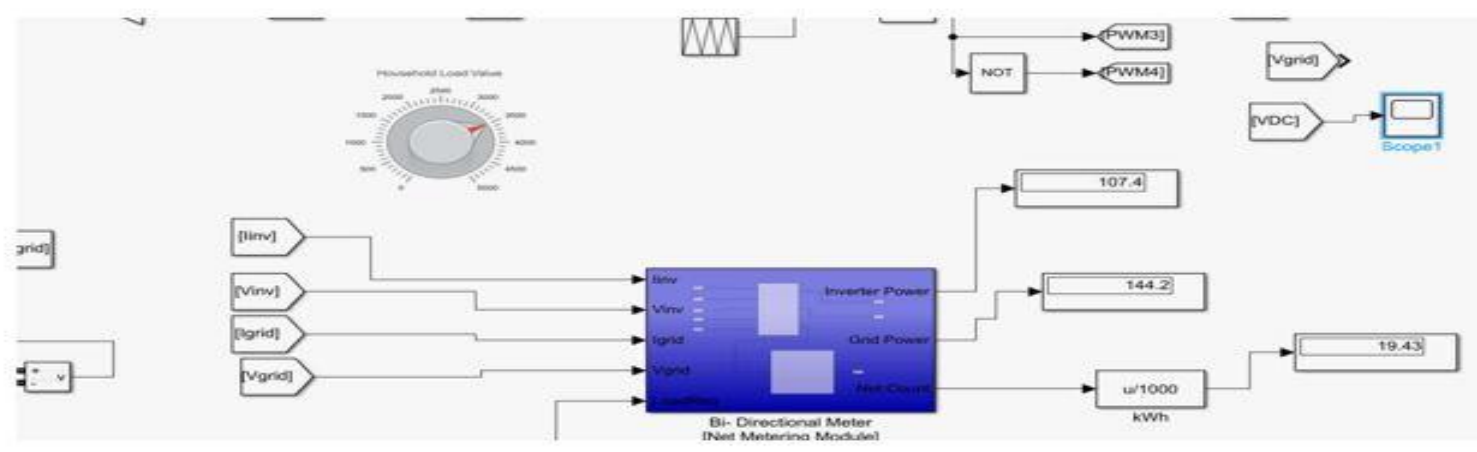

Figure 14. Bi-Directional Net Meter

E. Varying Irradiance
The response of the inverter was thus testing for varying conditions of irradiance via a repeating sequence block as seen in the Figure below

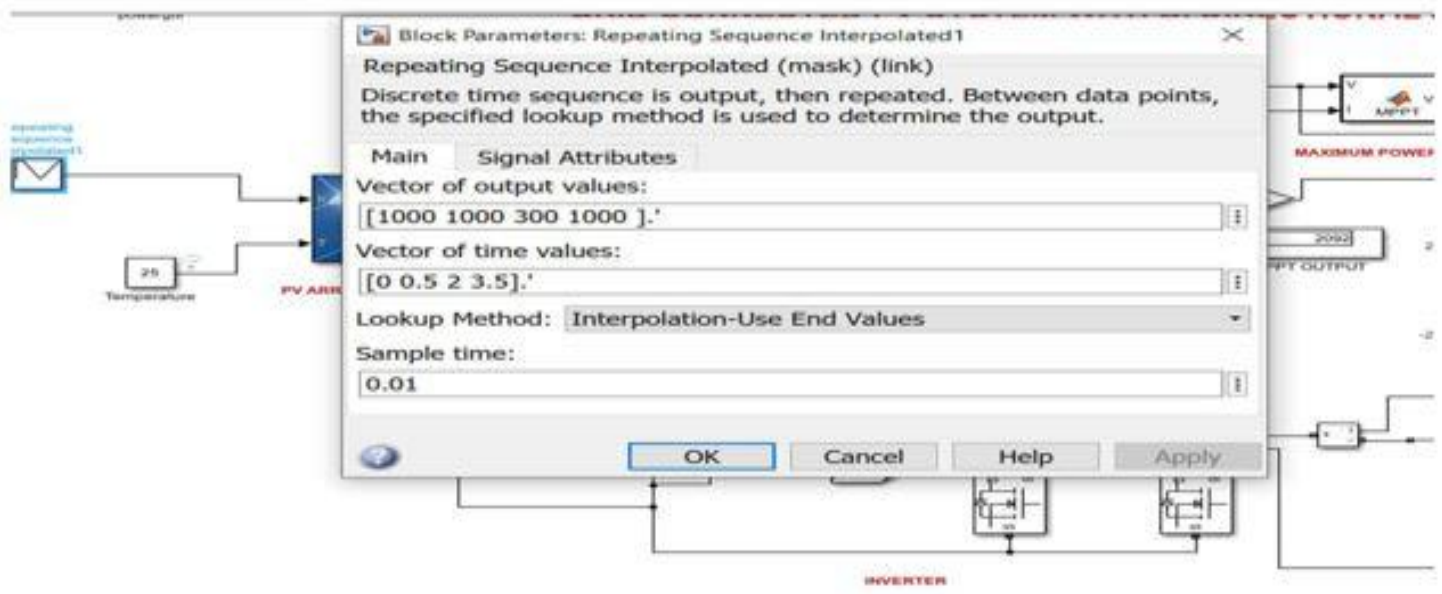

Figure 15. Repeating sequence for different levels of irradiance $\left(\mathrm{W} / \mathrm{m}^{2}\right)$ 
A variation in the level of irradiance consequently affects the peak voltage generated as clearly seen in the MPPT output over the given period.
The inverter response to the varying level of irradiance from $1000 \mathrm{~W} / \mathrm{m}^{2}$ to $300 \mathrm{~W} / \mathrm{m}^{2}$ is also seen in figure 16 in the current profile.

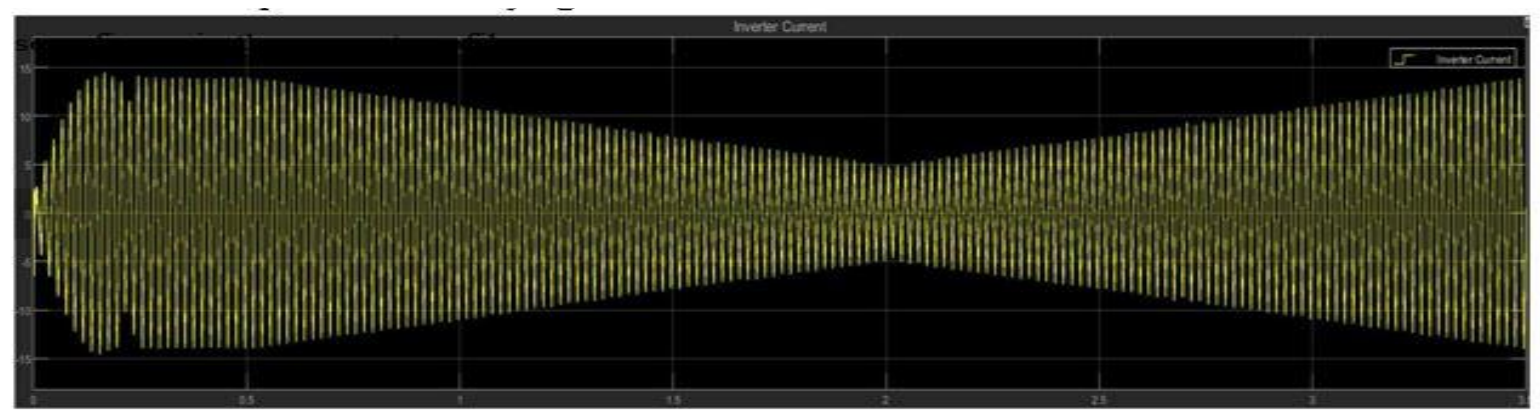

Figure 16. Inverter Current Profile for different levels of Irradiance

\section{CONCLUSION}

This research work has presented the design and simulation of a grid-connected photovoltaic system with a bi-directional net meter.

The study involves the implementation of a "Perturb and Observe" MPPT system, a phase lock loop (PLL), a Mosfet based single-phase inverter and a bi-directional metering unit. The result obtained from the simulation showed that the PV array operated at maximum power point irrespective of variations of solar irradiance. Simulation at $1000 \mathrm{~W} / \mathrm{m}^{2}$ and $800 \mathrm{~W} / \mathrm{m}^{2}$ at $25^{\circ} \mathrm{C}$ resulted in peak readings of $2091.8 \mathrm{~W}$ and $1665 \mathrm{~W}$ respectively.

The I-V characteristics of the designed on-Grid inverter showed a synchronized Grid-Inverter output as controlled by the integrated phase lock loop unit.

The designed counter-based bi-directional metering effectively supplied power from the grid when the simulated household load requirement was above the power generated by the inverter and vice-versa thus resulting in an overall smart system with Net Metering and billing capability.

The design and simulation were carried out via the Simulink platform of the Matlab software and the result obtained showed the designed system was functional and able to meet research objectives.

Further research can be done in the integration of suitable anti-islanding features and multi-stage inverter systems.

\section{REFERENCES}

[1]. Atiq, J., \& Soori, P. K. (2017). Modelling of a grid-connected solar PV system using MATLAB/. International Journal of Simulation: Systems, Science and Technology, 17(41), 45.1-45.7. https://doi.org/10.5013/IJSSST.a.17.41.45s

[2]. Adar, H. M., Chakraverty, A., Moore, D. H., Mur]ray, J. M., \& Loparo, K. A. (2012). Design and implementation of a specific grid-tie inverter for an agent-based microgrid. 2012 IEEEEnergytech, Energytech 2012, March 2015.https://doi.org/10.1109/EnergyTech.2012.6304676
[3]. Dolas, N. A., Sharma, R. B., \& Sindekar, P. A. S. (2020). Solar PV grid-connected system analysis. May, 7360-7364.

[4]. Hoft, R. G., \& Hoft, R. G. (1986). Self-Commutated Thyristor Inverters. Semiconductor Power Electronics, 239-268. https://doi.org/10.1007/978-94-011-7015-4_11

[5]. Johnson, B. A. (2013). Modelling and Analysis of a Pv Grid-Tied Smart Inverter'S Support Functions. Master's Thesis, May.

[6]. Karthikeyan, V., Rajasekar, S., Das, V., \& Pi, K. (2017). GridConnected and Off-Grid

[7]. Solar Photovoltaic System Grid-Connected and Off-Grid Solar Photovoltaic System (Issue May 2018). https://doi.org/10.1007/978-3-319-50197-0

[8]. Ibrahim, K. A., Gyuk, P. M., \& Aliyu, S. (2019). THE EFFECT OF SOLAR IRRADIATION ON SOLAR CELLS. 14(1), 20-22.

[9]. Maharaja, K., Pradeep Balaji, P., Sangeetha, S., \& Elakkiya, M. (2016). Development of bidirectional net meter in a gridconnected solar PV system for domestic consumers. 2016 International Conference on Energy Efficient Technologies for Sustainability, ICEETS 2016, April, 46-49. https://doi.org/10.1109/ICEETS.2016.7582897

[10]. Kahlane, A. E. W. H., Hassaine, L., \& Kherchi, M. (2014). LCL filter design for photovoltaic grid-connected systems. Third International Seminar on New and Renewable Energies, 8(2), 227 232.

[11]. Khatib, T., \& Elmenreich, W. (2016). Modelling of Photovoltaic Systems Using MATLAB ${ }^{\circledR}$ Modeling of Photovoltaic Systems Using MATLAB ® https://doi.org/10.1002/9781119118138

[12]. Mohanty, P., Sharma, K. R., Gujar, M., Kolhe, M., \& Azmi, A. N. (2016). PV system design for off-grid applications. In Green Energy and Technology (Vol. 196, Issue September). https://doi.org/10.1007/978-3-319-14663-8_3

[13]. Ositelu, O. (2010). "Design and Simulation of a Distributed PV System for Pennsylvania State University," Analysis, pp. 1-72, 2010.ed PV System for Pennsylvania State University. Analysis, $1-72$.

[14]. Phap, V. M. (2019). Study on Grid-Connected Photovoltaic System Using PSIM Program. 8(10), 706-710.

[15]. Rani, A., \& Sharma, G. (2017). A Review on Grid-Connected PV System. International Journal of Trend in Scientific Research and Development, Volume-1(Issue-4), 558-563. https://doi.org/10.31142/ijtsrd2195

[16]. Raut, D. B., \& Bhattrai, \& A. (2013). Performance Analysis of Grid-Connected Solar PV System Using Matlab. Simulink Rentech Symposium Compendium, 3(September), 48.

[17]. REN21 Renewables 2014 Global Status Report. (2014). Total world energy consumption by source 2013.

[18]. Rodrigues, E. M. G., Melício, R., Mendes, V. M. F., \& Catalão, J. P. S. (2011). Simulation of a solar cell considering a single-diode 
equivalent circuit model. Renewable Energy and Power Quality Journal, 1(9), 369-373. https://doi.org/10.24084/repqj09.339

[19]. Sreedevi, J., Ashwin, N., \& Naini Raju, M. (2017). A study on a grid-connected PV system. 2016 National Power Systems Conference, NPSC 2016, 0-5. https://doi.org/10.1109/NPSC.2016.7858870

[20]. Zipp, K. (2015). What are some common types of solar PV and storage installations? Solar Power World. https://www.solarpowerworldonline.com/2015/10/what-are-somecommon-types-of-solar-pv-and-storage-installations/ 